\title{
JÓVENES \& PUBLICIDAD Estereotipos, prejuicios, invisibilización y adultocentrismo
}
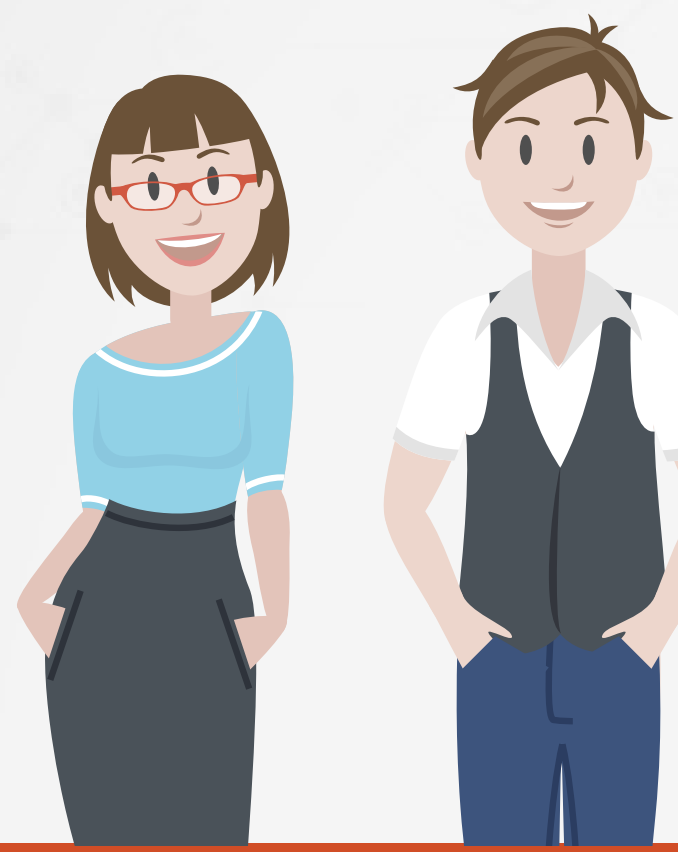

Janneth Arley Palacios Chavarro* Recibido. Marzo 22, 2017- Aceptado. Abril 18,2017

\section{RESUMEN}

El objetivo del presente artículo es contrastar la categoría de juventud, entendida como imaginario social instituido tradicionalmente, con la perspectiva de un grupo de estudiantes universitarios, a partir de sus enunciados sobre un conjunto de comerciales publicitarios.

Los resultados muestran que el imaginario social ha generado estereotipos, ha intentado homogeneizar e invisibilizar a los jóvenes, a lo que ha contribuido, de manera importante, la publicidad a través de su relato, pero también se hace evidente cierta resistencia de los participantes a esta reducción y visibilizan su papel propositivo, lejano a la concepción de consumidor pasivo y alienado que la crítica tradicional ha instaurado. No obstante, no deja de considerarse que tal papel sea también promovido por el relato mismo como parte de las tendencias publicitarias contemporáneas.

Se encuentra además que el imaginario adultocentrista de la juventud como etapa con características que contrastan con la adultez, responde a una simplificación que no contempla la posibilidad de que padres e hijos puedan compartir como "pares", es decir, como interlocutores que se validan mutuamente. Este señalamiento se muestra también como un requerimiento afectivo de amistad y de diálogo.

Palabras Clave: imaginario de juventud, relato publicitario, juventud, estereotipos, homogenización, invisibilización.

*Docente-investigadora del programa de Publicidad y Mercadeo de la Facultad de Ciencias de la Comunicación de la Fundación Universitaria Los Libertadores, Bogotá, Colombia. Email: japalaciosc@libertadores.edu.co 


\title{
YOUTH \& ADVERTISING \\ Stereotypes, prejudices, invisibilization and adultcentrism
}

\begin{abstract}
SUMMARY
The aim of this article is to contrast the category of youth, known as traditionally instituted social imaginary, with the perspective of a group of university students, from their statements about a group of advertising commercials.

Results show that social imaginary has generated stereotypes, has tried to homogenize and invisibilize to youth people and that advertising had contributed to this situation through its statement. But also, findings evident certain resistance of the participants to this reduction and show their propositive role, distantly to the conception of passive and alienated consumer that the traditional critique has restored. Nevertheless, it does not stop considered to be the possibility that such a role should be promoted also by the statement itself as part of the advertising contemporary trends.
\end{abstract}

Inside the findings we find that adultcentrism imaginary of youth people as stage with characteristics that contrast with the adulthood answers to a simplification that does not contemplate the possibility that parents and children could share as "peer", that is to say, as speakers who are validated mutually. This affirmation appears also as an affective need of friendship and dialog.

Keywords: youth imaginary, advertising statement, youth, stereotypes, homogenization, invisibilization.

\section{JOVENS \& PUBLICIDADE Estereótipos, preconceitos, invisibilização e adultocentrismo}

\section{RESUMO}

O objetivo do artigo presente é contrastar a categoria da mocidade, entendida como imaginário social, com a perspectiva dum grupo de estudantes universitários a partir de seus enunciados sobre um conjunto de propaganda comercial. Mas também se torna certa resistência evidente dos participantes a esta redução e visibilizan o seu papel propositivo, distante à concepção de consumidor passivo e alienado que a crítica tradicional estabeleceu. Não obstante, não deixa de ser considerado a possibilidade que tal papel seja também promovido pelo mesmo relato, como parte das tendências propagandísticas contemporâneas.

Dentro das descobertas está também o imaginário adultocentrista da mocidade como fase com características que contrastam com a maioridade responde a uma simplificação que não contempla a possibilidade de que os pais e as crianças podam compartilhar como "casais", quer dizer, como oradores que são validados mutuamente. Esta sinalização também é mostrada como a exigência afetiva de amizade e de diálogo.

Palavras chaves: imaginário de mocidade, relato publicitário, mocidade, estereótipos, homogenização, invisibilização, 
Introducción

a idea de juventud cobra diferentes sentidos según el área del conocimiento desde la cual se aborde y de acuerdo con las condiciones sociohistóricas de su producción. Tradicionalmente, la juventud ha sido entendida como una "etapa del desarrollo humano comprendida entre la pubertad fisiológica y el reconocimiento de la condición de adulto, en la que el individuo se prepara para asumir los compromisos sociales." (Feixa, 1998 citado por Martínez \& Barragán, 2008). Esta categoría empieza a tomar interés por las áreas sociales a partir de la segunda década del siglo $\mathrm{XX}$ y adquiere su mayor despliegue de análisis en las décadas de los sesentas cuando en el mundo y en Colombia, comienzan a cobrar protagonismo los movimientos sociales, políticos y culturales promovidos por jóvenes (Cepeda, 2008).

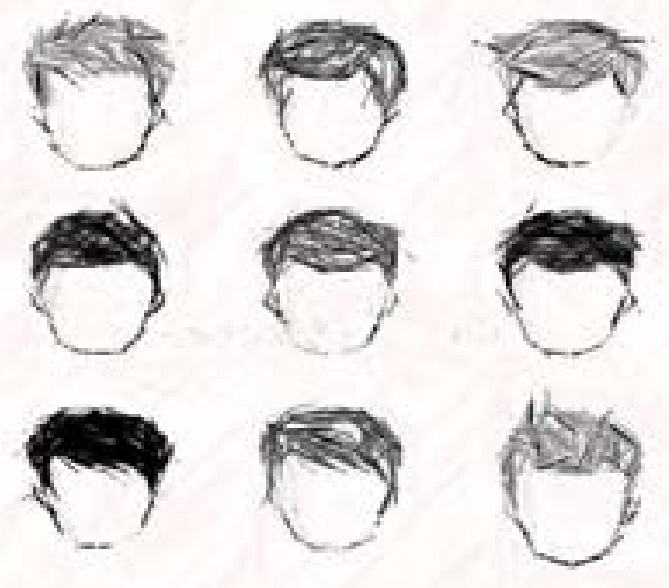

De acuerdo con Campos (2010), la edad es un criterio ordenador de la realidad. No obstante, tal criterio no es suficiente para concebir la juventud como categoría universal, pues esta se trata de una "invención" o construcción histórica, no de un dato natural (Padres, 1993; Feixa, 2006; Frith, 1984). "Una mirada más atenta nos muestra que tenemos no uno, sino muchos jóvenes. Estos están dispersos por el espacio geográfico y social, se enfrentan a problemas, condiciones y expectativas diferentes." (Campos, 2010, pp. 121- 122).

Según Martínez \& Barragán (2008), Feixa (1998) plantea algunas caracterizaciones generales del concepto de juventud desde el contexto socio-cultural, las cuales se traducen en cinco modelos históricos que enmarcan la categoría. El autor parte de la etapa de las sociedades primitivas y sin Estado, en las cuales se llevaban a cabo ritos de paso para marcar el acceso de los púberes a las actividades productivas, reproductivas y de defensa; pasa luego a la etapa de las sociedades clásicas, en las que el joven se formaba durante un tiempo para luego ser reconocido como adulto y, en consecuencia, propiamente como ciudadano; después, analiza la tercera etapa, la del contexto medieval, donde la relación con la edad parece desaparecerse, y después se centra en la cuarta etapa, la de la sociedad industrial, en la que surge el arquetipo de juventud tal y como lo conocemos actualmente:
En esta época, con la caracterización que realiza Rousseau en 1762, irrumpe propiamente el concepto de juventud; no obstante, aparece masivamente a finales del siglo XIX y el $X X$, como consecuencia de las transformaciones impulsadas por la industrialización y el liberalismo en los ámbitos de la familia (que se preocupa más por los niños), la escuela (instrumento de reiniciación social), el ejército (para hacerse hombre) y especialmente el mundo laboral, que implica ingresar al sistema productivo y mayor preparación técnica para el manejo de las máquinas. Los jóvenes son expulsados del mercado laboral. A finales del siglo XIX, y con fuerte incidencia de la psicología, la antropología y la sociología, se descubre la adolescencia y luego en la primera mitad del siglo $\mathrm{XX}$ este concepto (reservado a los jóvenes burgueses) se democratiza y aparecen asociaciones dedicadas a orientar el tiempo libre de aquellos que no son niños ni adultos: los jóvenes (Martínez \& Barragán, 2008, p. 358).

De acuerdo con la historiografía canónica, afirma Feixa (2006) que el surgimiento de la adolescencia como noción se sitúa también en los orígenes de la sociedad industrial, pero no se democratizó sino hasta comienzos del siglo $\mathrm{XX}$, cuando cambios en la escuela, el mercado de trabajo, la familia, el servicio militar, las asociaciones juveniles y el mundo del ocio, posibilitaron que se legitimara una generación consciente de crear una cultura propia y distintiva, diferente a la de los adultos.

Una quinta etapa del desarrollo histórico de la categoría de juventud, la post industrial, responde a las dinámicas de modernización, tecnología y globalización; ahí, la juventud adquiere su mayor importancia y es protagonista del desarrollo económico, social e industrial de los países, configurándose como eje clave para la sociedad capitalista, el mercado y desde luego, el consumo. En este marco, Martínez \& Barragán (2008) comprenden que en las actuales circunstancias, hablar de joven o incluso de juventud desde perspectivas generalistas o universalizantes resulta anacrónico, pues la idea de juventud constituye una amalgama de diferentes horizontes, subjetividades y experiencias, que alimentan diversas formas de ver e interpretar el mundo: "ser joven ya no es una cuestión de edad; tienen que ver con los usos y costumbres que permiten narrarse como sujeto juvenil” (Martínez \& Barragán, 2008, p. 359).

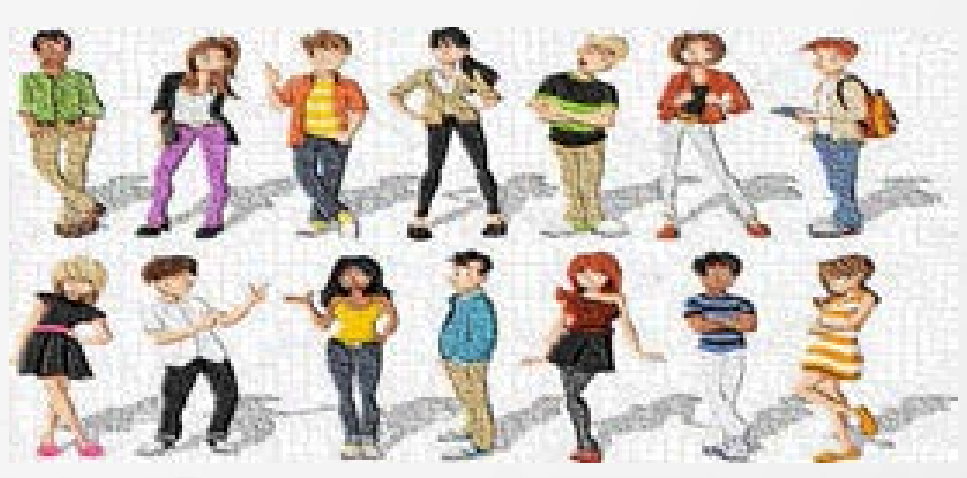

La relevancia y visibilidad de la juventud en el mundo contemporáneo, coincide con una suerte de "culto a lo joven" cada vez más marcado en las sociedades occidentales, que se caracteriza fundamentalmente por el rechazo de la uniformidad, la valorización de la corporeidad y la organización de la existencia en torno a los estereotipos juveniles presentados por los medios de comunicación (Martínez \& Barragan, 2008). Estas características posibilitan la transformación de lo juvenil en industria cultural: "se trata, por lo tanto, de un mecanismo en el que se sustraen elementos 
culturales juveniles, para ponerlos de nuevo en circulación convenientemente depurados o alterados". (Espín-Martín, 2002, p.72, citado por Martínez \& Barragan, 2008, p. 360).

Para Feixa, la historia del siglo XX puede concebirse como una sucesión de generaciones juveniles que evidencian las diferentes formas en las que los jóvenes hacen presencia en la escena pública en diversos contextos socio-históricos: "la reforma, la revolución, la guerra, la paz, el rock, el amor, las drogas, la globalización o la antiglobalización". A cada una de las décadas del siglo XX, el autor le asigna una letra comprendida entre la $A$ y la $R$, para designar ciertos rasgos metafóricos que la caracterizan. La generación "A" es la adolescente; su característica principal es la amplia presencia de jóvenes en las instituciones educativas, con diferencias marcadas entre clases sociales: "Mientras para los jóvenes burgueses significaba un período de moratoria social dedicado al aprendizaje formal y al ocio, para los jóvenes obreros era una de las consecuencias de la segunda industrialización, que los expulsaba del mundo del trabajo y los condenaba al paro forzoso y a la calle." (Feixa, 2006, p. 4).

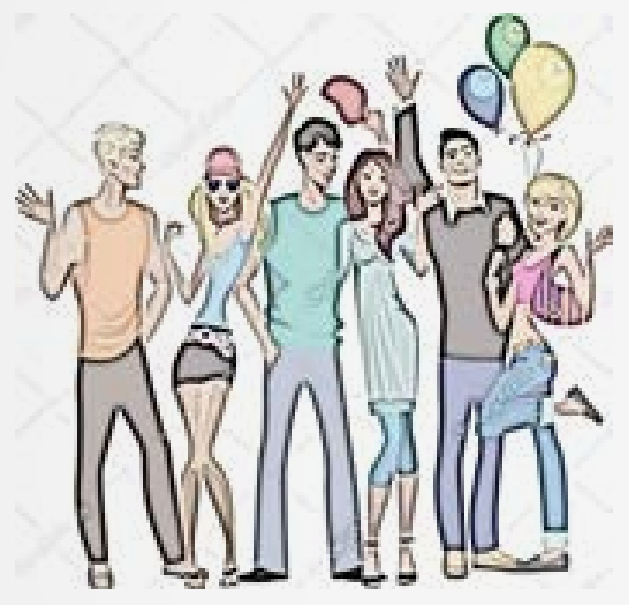

Esta generación coincide históricamente con la publicación del primer tratado teórico sobre juventud, llamado "Adolescencia: su Psicología y sus relaciones con la Antropología, la Sociología, el Sexo, el Crimen, la Religión y la Educación" (1904), por Stanley Hall, quien, partidario del concepto de evolución biológica propuesto por Darwin, propone una teoría del desarrollo psicológico que considera que cada espécimen recrea la historia del género humano; desde esta perspectiva, la adolescencia es un período de transición, de storm and stress (tormenta y agitación), equivalentes al sturm und drang (tormenta e ímpetu) del romanticismo alemán, lo cual da cuenta de la naturaleza "crítica" de esta fase de la vida (Hall, 1904). De acuerdo con Feixa, el trabajo de Hall "contribuyó a difundir una imagen positiva de la adolescencia como el paradigma del progreso de la civilización industrial, celebrando la creación de un período de la vida libre de responsabilidades, caracterizado por el conformismo social". (Feixa, 2006, p. 5).

Feixa (2006) nombra otras generaciones de jóvenes:

B (Boy Scout), K (Komsomol), S (Swing), E (escéptica), R (Rock), H (Hippy), P (Punk), T (Tribu).

Entre estos tipos de jóvenes, nombra la $E$ (escéptica), la cual surge luego de la Segunda Guerra Mundial y da lugar a jóvenes desencantados y sin fe luego de ver caer sus ideales de juventud (p.8), y la generación $\mathrm{R}$, que está caracterizada por el desarrollo de las comunicaciones, el uso masivo de Internet como plataforma de comunicación y las nuevas formas de comunicación e información.

Eso genera nuevas formas de protesta, como las marchas antiglobalización, donde jóvenes de distintos países acuden a manifestaciones convocadas por internet, propagadas por flyers y gestionadas por teléfonos móviles. Y también nuevas formas de diversión (como las macroraves), donde se utilizan formas de convocatoria semejantes para finalidades lúdicas. Pero también surgen nuevas formas de exclusión social que podríamos llamar cibernéticas ( $i p a r a$ acceder a la red hace falta tener una llave de acceso!). La red genera comunidades virtuales, pero también nuevas soledades como los hikikomoris, adolescentes japoneses que se encierran en su habitación digital (Feixa, 2006 p.14).

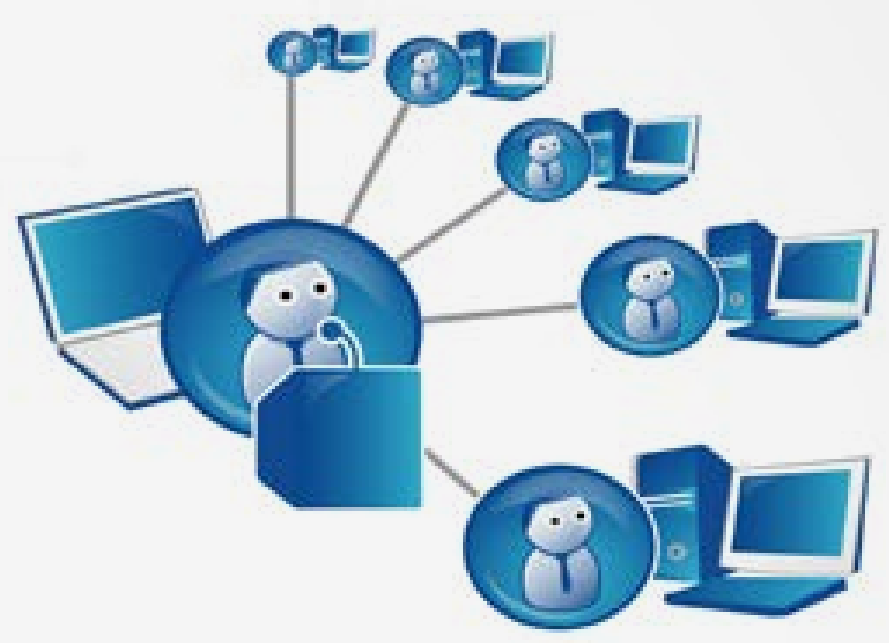

Para otros autores, es después de la Segunda Guerra Mundial cuando los jóvenes adquieren una mayor relevancia en la escena pública, gracias a los medios de comunicación, pues "el joven ha ocupado un lugar importante en la producción académica, en los discursos políticos y los contenidos de los medios en los últimos 50 años" (Campos, 2010) y es desde este planteamiento que surge el interés por abordar el concepto de juventud desde la perspectiva de un grupo de estudiantes universitarios, quienes a partir de sus propias experiencias, sentimientos y opiniones construyen su imaginario sobre lo que es la juventud y cómo la publicidad a través de su relato media en dicha construcción social.

1. Juventud como categoría y como imaginario social instituido

De acuerdo con Hurtado (2004), la juventud existe como categoría en tanto se han generado condiciones históricas, sociales y espacios que han permitido su existencia y visibilización, como los posibilitados por los medios, el estudio que ha ameritado esta categoría por parte de diferentes disciplinas. De esta manera, la juventud se constituye como una forma de institución constituida mediante relaciones sociales, procesos de aceptación, e incluso, legitimación y sanción social (Hurtado, 2004). Sin embargo, en las actuales perspectivas "los sujetos jóvenes no sólo han sido determinados como tales, encarnando la categoría, sino que son capaces de re-significarse en su identidad (es), en las múltiples y heterogéneas formas de vivir como joven, de sentirse joven (es), pero además de re-significar sus formas de relación, así como los espacios simbólicos que habitan". (Hurtado, 2004). 
Siguiendo a Hurtado (2004), a la categoría de juventud le han correspondido diferentes imaginarios sociales, como los enunciados en párrafos anteriores, desde los cuales se ha intentado explicarla. Estos imaginarios se han venido instituyendo dependiendo del contexto social en el que se encuentren, o del momento histórico en el que se produzcan. Así, se pueden encontrar los siguientes imaginarios de juventud:

Lo juvenil desde la transición: entendido como ciclo "intermedio" de vida determinado por la edad, desde donde se desarrollan lineamientos para la construcción de políticas públicas; la juventud, dentro de este imaginario, constituye una etapa importante de preparación e integración social como grupo etario homogéneo que tiene como elemento común la edad.

Lo juvenil como etapa de crisis: este imaginario presenta al joven como un sujeto en crisis, que necesita autoridad y ley. Según el autor, este imaginario ha sido instituido tan fuertemente que ha producido la estigmatización social del joven como delincuente, desadaptado, irresponsable y, por consiguiente, objeto de control. De ahí la legitimación de formas de control social de los jóvenes.

Los jóvenes como actores estratégicos del desarrollo y ciudadanos productores: en este imaginario se plantean dos perspectivas: la del joven como agente de cambio y motor de transformación social, y la del joven como problema de desarrollo que da lugar a una población vulnerable a fenómenos como el desempleo, la marginalidad y otras formas de exclusión (Hurtado, 2004).

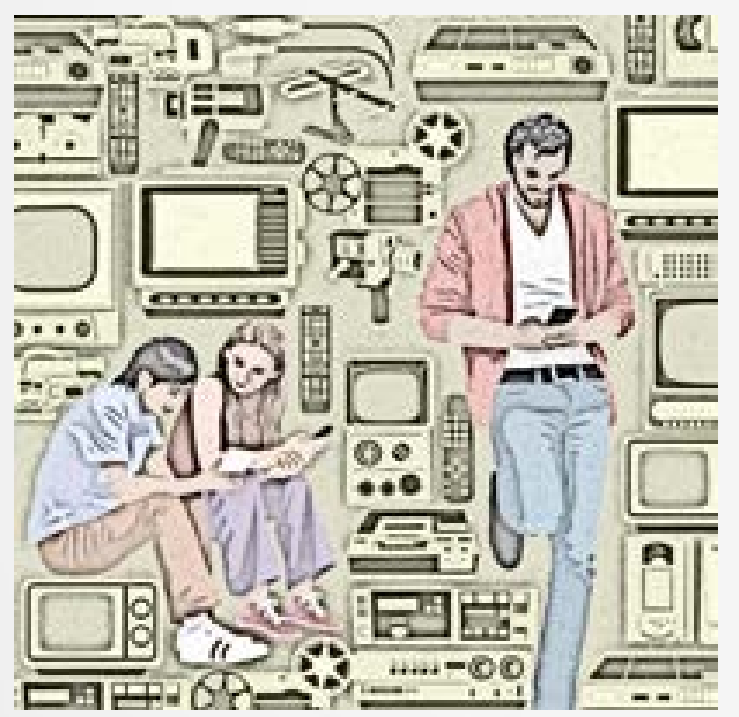

Alo anterior se suma un conjunto de características que subyacen a y han sido producto de estos imaginarios sociales instituidos de juventud: a) homogeneizantes, al considerar a las personas jóvenes bajo un conjunto de rasgos similares: necesidades, visiones $y$ condiciones de vida iguales; b) estigmatizantes, es decir, generadores y verificadores de estereotipos; en este punto, vale la pena señalar que varios estudios muestran cómo el imaginario de juventud convertido en estereotipo ha sido empleado por la publicidad como mecanismo de persuasión, en particular, en lo concerniente a los lugares comunes relacionados con el género y los que le atañen a la televisión por su repercusión visual.

En este punto, vale la pena recordar que los estereotipos son creencias positivas o negativas que caracterizan a un grupo que permiten incluir o no, personas en diferentes grupos sociales (VelandiaMorales \& Rincón, 2014) los estereotipos negativos son llamados prejuicios, haciendo referencia a las opiniones que sin evidencia son tomadas como verdad; c) invisibilizadores de las mujeres, ya que se asume que los jóvenes son hombres, desconociendo las especificaciones de género, y por último, d) desvalorizadores de lo femenino (Hurtado, 2004).

Estas características han aportado significativamente a la manera como se comprenden, se asocian y se valoran a las personas que se ubican dentro de la categoría de juventud, buscando además legitimar acciones que van desde el control social, hasta la forma en que los jóvenes son presentados y re-presentados en los diferentes medios de comunicación. Así, estos imaginarios sociales de juventud han generado exclusión y segregación, no solo en cuanto a lo femenino, sino también en lo relativo a lo diverso, pues han ignorado las particularidades, los contextos, y las experiencias singulares de los jóvenes. En este sentido, Velandia-Morales \& Rincón (2014), afirman que "los estereotipos de género van más allá de una simple categorización o división social, ya que pueden hasta definir la ocupación de hombres y mujeres; además, estos se relacionan con la discriminación y el prejuicio en función del poder y estatus de unos y otros, lo que evidencia la importancia que tiene el estudiar cómo estos son representados en diferentes ámbitos sociales, por ejemplo la publicidad". (p. 519).

Siguiendo este orden de ideas,

\begin{abstract}
Lo que se legitima primordialmente es la mirada homogenizante y de desviación social que, desde la perspectiva adultocéntrica trata de explicar e intervenir a los jóvenes y por último, el imaginario de juvenilización propuesto por la industria cultural, en la cual se visibiliza al sujeto joven, en tanto consumidor, al cual desde la carencia se le crea un flujo incesante de necesidades y deseos (Hurtado, 2004, p. 172)
\end{abstract}

Este panorama contemporáneo sobre la juventud coincide con la afirmación de Bourdieu, según la cual "La juventud no es más que una palabra" (Bourdieu, 1990), para designar un habitus, un entramado de relaciones. En la actualidad, acorde con tal postura, parece haber un énfasis en lo relacional y lo contextual, más que en lo psicobiológico, a la hora de conceptualizar lo juvenil, las juventudes y categorías similares. En este sentido, para Duarte (2012) “lo juvenil es a nuestro juicio la categoría más comprensiva, en tanto da cuenta de la condición relacional del ser joven y de las distintas formas de concebir-producir jóvenes, juventud (es) y juvenilización" (p. 101).

\subsection{El papel del consumidor en la publicidad}

Varios autores coinciden en señalar que la publicidad emergió como parte del discurso que trajo consigo la Modernidad (Colón, 2001) y su sentido hegemónico. En el caso colombiano, se afirma que está inspirada por la experiencia extranjera, además de impulsar y promocionar mercancías y productos de consumo, tenía la intención de expandir la hegemonía económica y cultural de Estados Unidos y de Europa, a través del patrocinio por parte de sus empresas a la actividad publicitaria local, para ello, uno de los principales recursos era y ha sido la imagen, con la cual los productos se hacían más atractivos sumado a nuevas formas de uso que invitaban al consumo (Villadiego, Bernal \& Urbanczyk, 2006). 
De acuerdo con lo anterior, el relato publicitario se instaura en la sociedad colombiana como pieza clave para dinamizar la economía, sostener los ideales capitalistas y mostrar nuevos estilos y formas de vida posibles y aparentemente alcanzables para la incipiente sociedad de consumo, promoviendo una transformación no solo comercial sino también cultural, pero además,

gracias al relato publicitario, las necesidades por siempre causantes del consumo, verán ampliar su espectro, ya que en adelante, y en respuesta a ellas, las compras no sólo se producirán motivadas por el ritmo lento del desgaste de productos básicos para la vida (como la alimentación, el alojamiento o el vestido), sino que encontrarán nuevas motivaciones en la apelación a las distinciones, necesarias en una sociedad en la que las aspiraciones a un mejor vivir no serán más la propiedad exclusiva de una clase social dominante. (Villadiego, Bernal \& Urbanczyk, 2006, p. 164).

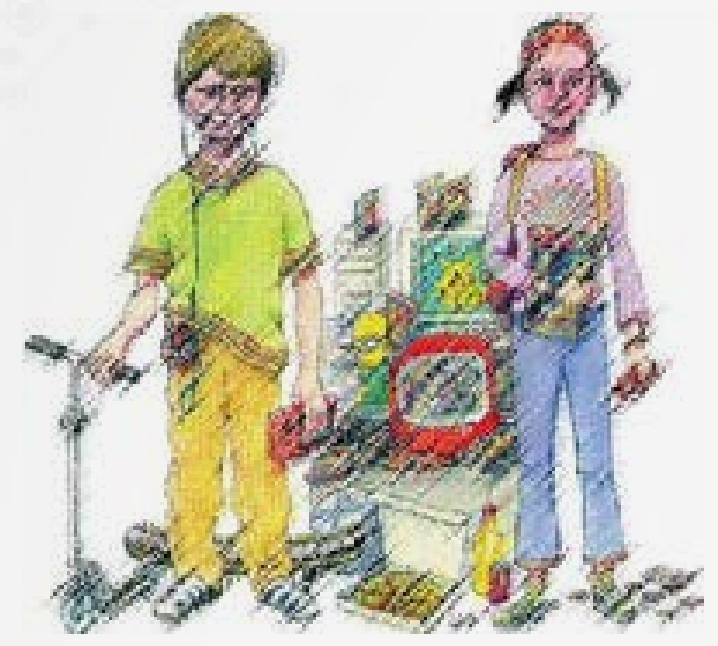

Desde esta perspectiva, la publicidad posibilitará y propondrá una nueva forma de acción a partir del consumo y generará, presumiblemente, elecciones basadas en la decisión individual. Sin embargo, a la par de este discurso, existe en la actualidad un debate crítico a la publicidad que plantea que esta es una herramienta de alienación y persuasión cuyo principal propósito es modificar las respuesta del receptor en tanto sujeto pasivo, indefenso e incapaz de tomar sus propias decisiones (Villadiego, 2012). En contraste, esta misma autora sostiene que a la luz de las diferentes transformaciones del mundo cotemporáneo en los ámbitos cultural, social y económico, el papel de los consumidores ha cambiado, lo cual los conduce a "comportarse diferente y a mostrarse más despiertos, exigentes e inquietos frente a todo lo que se les ofrece, no solo por las vías del ATL (medios masivos de comunicación), sino también por el BTL (medios no masivos, o podríamos decir, para ser más precisos, medios personalizados)." (Villadiego, 2012).

Esta situación expone la necesidad de considerar al consumidor como un sujeto partícipe, activo y recreador dentro de las dinámicas de consumo, lo cual, siguiendo a Villadiego (2012), también ha transformado las formas de relación, cercanía y comunicación entre la industria publicitaria y los consumidores.

Evidentemente, ya no se trata solo de informar sobre la disponibilidad de un producto en el mercado o de proponer un estilo de vida idealizado para los consumidores, en el que la oferta publicitaria satisface a la medida las necesidades y deseos de los consumidores (Casetti, 1994, p 23), sino que hemos entrado en una nueva etapa, donde la publicidad debe ser divertida, entretenida, inteligente, pero sobre todo capaz de establecer una especie de juego, trazado en la narrativa de la publicidad, para establecer una nueva relación, un nuevo diálogo entre los anunciantes y los consumidores". (Villadiego, 2012, p. 133).

En consecuencia, desde una postura no tan apocalíptica, el consumo, la publicidad, los anunciantes y el consumidor también proponen líneas de acción que interpelan las esferas de lo social, al confrontar las formas de pensar y actuar de las personas en lo cultural, al proponer pautas, creencias, rituales y comportamientos que terminan siendo compartidos por una sociedad, y en lo político, porque también desde la acción de consumo el individuo ejerce y desarrolla su autonomía, su derecho a decidir y su actuar ciudadano, o al menos "negocia" con las condiciones del sistema socioeconómico regente.

Con esta perspectiva, se busca ampliar y complejizar la mirada sobre el objeto publicitario, ya que a la publicidad no se le examina exclusivamente desde el punto de vista de su dimensión económica, sino que, además, se intenta su comprensión en términos comunicativos y culturales. En este sentido, se trata de trascender la vieja teoría en la que al consumo se le examina como un efecto de la incitación publicitaria, para empezar a ver en esa relación no un efecto impuesto por el anunciante, sino un juego, esto es, una dinámica de intercambios en la que las acciones del anunciante no tienen siempre el poder para imponer, controlar o dominar a su antojo a los consumidores, sino que, por el contrario, buscan invitar, interpelar y llamar la atención de los consumidores para que participen del juego" (Villadiego, 2012, p. 133).

Desde las posturas expuestas en los anteriores apartados y en contraste con la información recogida mediante los enunciados de los participantes en los grupos focales, organizados en el marco de la indagación sobre imaginarios de juventud que da lugar a este artículo, los resultados de este tipo contribuyen a matizar la crítica hacia el relato publicitario, pues como se observará luego, los jóvenes no siempre reciben los mensajes publiciarios pasivamente, sino que son capaces de controvertirlos, contrastarlos y hasta considerarlos absurdos o poco relacionados con su cotidianidad, además de identificar en ellos claras intenciones de persuasión

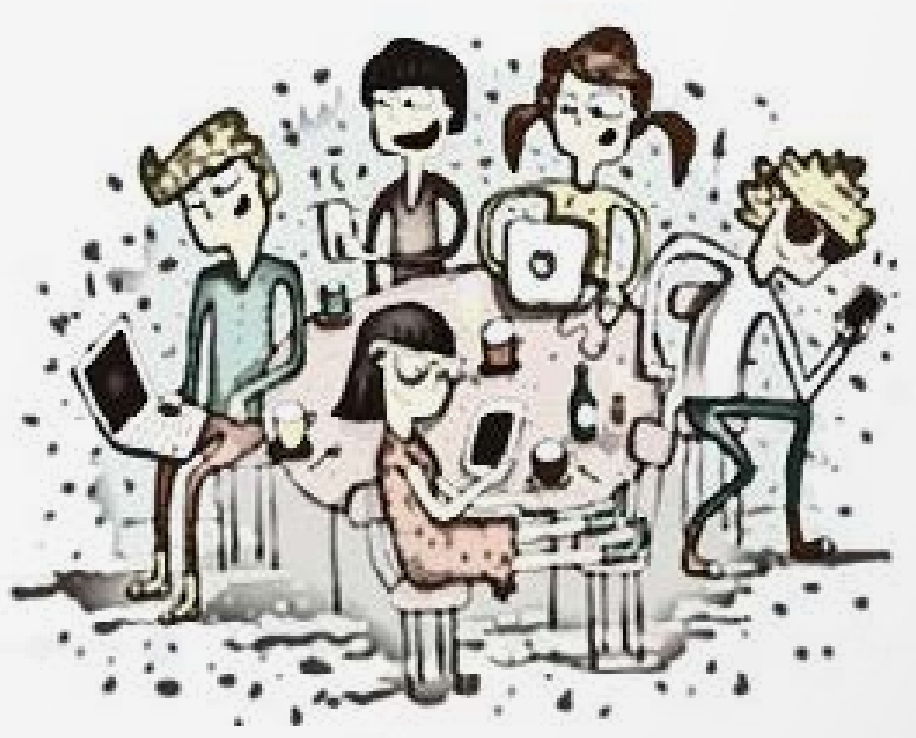




\section{Metodología}

En este artículo se mostrarán específicamente los resultados relacionados con los contenidos asociados con los imaginarios de juventud presentes en los enunciados de los participantes de los grupos focales y respecto a las categorías estereotipos y prejuicios, invisibilización y adultocentrismo, buscando contrastar el imaginario social instituido tal y como ha sido estudiado por Hurtado y otros autores, con las apreciaciones de un grupo de estudiantes universitarios, tomando como excusa el relato publicitario. La metodología propuesta recoge herramientas metodológicas cuantitativas y cualitativas que permitieron acercarse a los imaginarios de juventud. Entre las herramientas cuantitativas empleadas estuvo una encuesta realizada a 136 estudiantes activos de una prestigiosa Institución Universitaria de Bogotá, para recoger datos relativos a la edad, el género, $y$, la recordación de comerciales en los últimos dos años.

Esta última información fue relevante para seleccionar los comerciales, las temáticas y significantes comunes vinculados a ellos. Así se establecieron cuatro comerciales para el análisis: Sprite - En mi cuarto todo se vale ¿y? [1]; Open English - Persueychon [2] Davivienda - Corresponsal Ricardo Jorge: Todos (Mundial Brasil 2014) [3] y Old Spice- Desata tu lado salvaje [4]. Estos datos guiaron el diseño de los grupos focales y la elaboración de las preguntas orientadoras. No obstante, en la fase cualitativa de la investigación fue donde se obtuvo la mayor parte de la información analizada: se llevaron a cabo cuatro grupos focales con un total de 46 participantes, cuyos enunciados fueron útiles y relevantes para identificar los imaginarios de juventud construidos y someterlos a un análisis categorial.

\section{Resultados}

\subsection{Estereotipos y prejuicios}

Esta categoría permitió identificar y analizar qué estereotipos de juventud son percibidos por los estudiantes a través del relato publicitario, en este caso, a partir de los comerciales visionados.

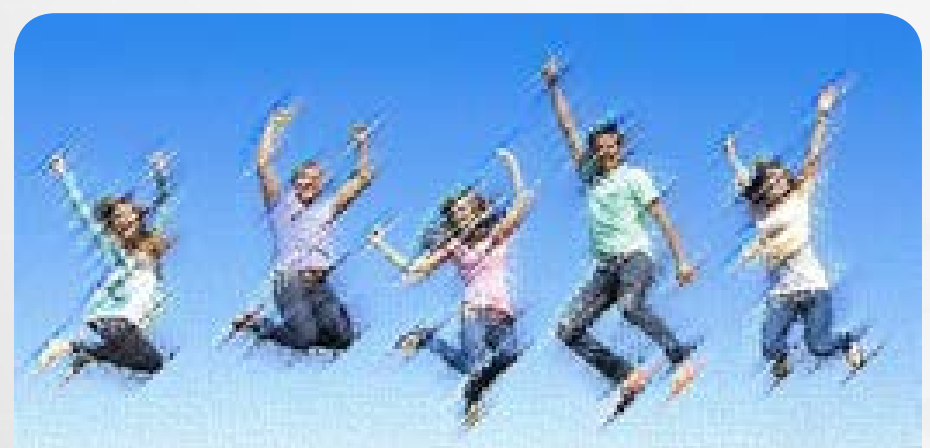

El comercial de Sprite - En mi cuarto todo se vale ¿y?, hizo que los participantes detectaran una serie de características que se acercan a un imaginario de juventud ya clásico: "salir de lo común" (carácter atípico), innovación, gracia, curiosidad, expresividad, alegría, emoción, libertad. Aunque los participantes identificaron exageración en los ademanes del personaje (en su particular baile), lo vieron como necesario, innovador y gracioso, y mostraron una marcada tendencia hacia la identificación.

La exageración propuesta en el comercial es particularmente lo que genera atención, dice participante de grupo focal: "Pues a mí me parece como exagerado y curioso cuando hace lo del gato, porque digamos a mí me pasa que yo a veces pongo música con mi esposo y nos ponemos a bailar, $y$ cuando llega mi suegro nos quedamos ahí quietos (risas) nos ponemos a hacer oficios (...) pero tampoco es para agacharme y hacer como un gato, tampoco". El tono humorístico que maneja la pauta ayuda a darle relevancia a la escena.

Aun cuando se reconoce el estereotipo del joven alegre, extrovertido y sensible, también es necesario mencionar que el presentado en la pauta no es el tradicional en tanto sexy, simpático, corpulento, situado en entornos elegantes; allí se muestra un personaje poco corpulento, algo tímido pero expresivo.

El contexto es intimista: una habitación ambientada siguiendo los criterios de la década de los ochentas del siglo XX. El modelo tradicional de joven se ve reconfigurado, así, por la versión popular de joven. "Cuando nosotros [los jóvenes] estamos en un ambiente que nos da confianza, somos expresivos, bailamos, nos sentimos en confianza para hacer lo que nos gusta, lo que nos inspira.

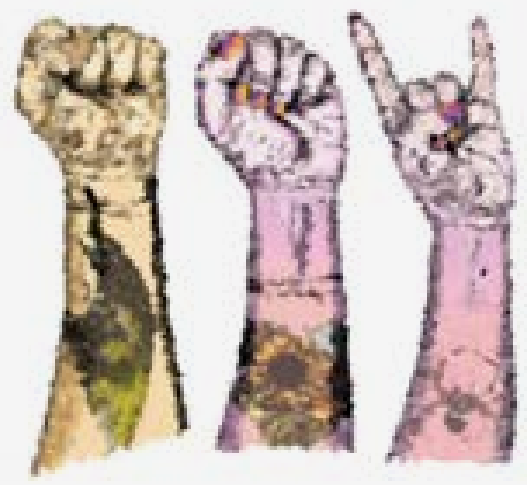

Los rasgos que componen ese imaginario descrito antes fueron, en su mayoría, señalados como cualidades: "Es más fácil identificar cualidades que defectos. Ese joven del comercial es una persona como extrovertida, como alegre, habría que verlo en otro escenario. Hay muchas personas que son cultas, calladas, pero vaya a ver uno qué hacen". "Hay personas que no se expresan libremente por el qué dirán".

Algunos participantes señalaron rasgos estereotipados como: "Ese tipo de comerciales muestra lo que la gente puede pensar que es un joven. Es decir alguien extrovertido, que solo piensa que está, que tiene la libertad a medias, que no puede ser libre afuera. Es una idea equivocada de lo que puede ser un joven (...)".

Indica un participante del grupo focal: "Digamos que los estereotipos no son lo mismo aquí en Colombia que nos parece como muy chistoso, a una mujer o una joven de 17 años en Afganistán donde si hace eso (...) su cultura es diferente..."

Quizás el imaginario de juventud que construyen los jóvenes puede estar adecuándose críticamente al reconocimiento de la diversidad contextual y 
a la creciente juvenilización de las sociedades posindustriales, en las que las expresiones consideradas juveniles son cada vez más validadas y en las que todos quieren permanecer jóvenes.

Esta otra intervención, va en el mismo sentido: “(...) Para mí sí está estereotipando la idea de lo que es un joven y de cómo este se tiene que comportar en determinados aspectos". Revelan estas palabras que el estereotipo delimita rígidamente lo que es y lo que no es propio de la juventud, dejando por fuera de la categoría a quienes no cumplan ciertas condiciones (extroversión, espontaneidad, alegría, extravagancia).

El clásico imaginario de juventud descrito anteriormente no es tan monolítico, sino que presenta fisuras y un carácter fluido proveniente del reconocimiento de un contexto global complejo y cambiante, con subcontextos diversificados, todo lo cual desemboca en la reticencia de los jóvenes a ser reducidos por la imagen estereotipada que el relato publicitario presenta.

No obstante, este proceso de permanente construcción y reconfiguración podría estar respondiendo, en último término, al mantenimiento de ciertos imaginarios que aunque superficialmente cambien, en el fondo continúan disimulando, por medio del relato publicitario, ciertas condiciones sociales problemáticas. El exitoso "joven Clío", precoz empresario que hace mucho dejó de bailar en su habitación a solas para vérselas de frente con los adultos y producir envidia en ellos, es justamente un ejemplo de la capacidad articuladora de los imaginarios que la publicidad siempre ha sabido aprovechar. Se trata de la nueva cara del otrora rebelde sin causa, ahora más responsable, más apetecible por una adultez menos "seria", más dispuesta a prolongar su juventud. En este sentido,

\begin{abstract}
Sabemos que las instituciones pueden cambiar rápidamente, adaptarse, y los roles también, pero para que se dé una articulación entre las dinámicas institucionales y los proyectos individuales, ciertos imaginarios deben permanecer. El campo publicitario ha aprovechado históricamente esta capacidad articuladora de los imaginarios para disimular condiciones objetivas problemáticas (inequidad, informalidad, falta de movilidad ascendente) que requieren un análisis profundo". (García y otros, 2012, p. 264).
\end{abstract}

En contraste, el comercial de Old Spice, "Desata tu lado salvaje", viene a apoyar el tradicional imaginario de hombre deseado y exitoso. Las características que lo describen son "aventurero", "confiado", "seguro": "Es un hombre que no solo se pasa en la oficina, sino que tiene la manera de vivir aventuras y tiene experiencias en las que necesita estar fresco, oler bien"; "Creo que el comercial si muestra un estereotipo de un hombre extrovertido, que no siempre está en situaciones extremas sino que en un ambiente tranquilo y controlado él va a estar protegido y con la confianza de que no va a tener sudoración"; "Ponen a los hombres en diferentes espacios y situaciones para mostrar que va a tener la seguridad de no tener que transpirar y que el producto le va a ofrecer durabilidad".

El estereotipo que ahí está operando se vincula con el del joven exitoso descrito antes. Solo que ahora ya no se trata simplemente del que triunfa precozmente, sino que además mantiene esos rasgos salvajes propios de la juventud: no solo está en la oficina, sino que experimenta aventuras y luce bien, está fresco todo el tiempo. Entonces, vemos que ya no se trata simplemente de un estereotipo, sino de todo un imaginario complejo, mutante, que articula características aparentemente disímiles: trabajadorhedonista; aventurero-responsable; despreocupadoprolijo. Es un imaginario que justamente se sitúa en la intersección entre el joven y el adulto, que trata de recoger rasgos estereotipados de ambas categorías para hacerlos converger de manera que tanto a jóvenes como a adultos (y sus posibles híbridos) les resulte atractivo.

\subsection{Invisibilización}

En su mayoría, los participantes en los grupos focales coinciden en que la publicidad, en este caso los comerciales, acuden a metáforas, exageraciones y estereotipos para representar situaciones que logren suscitar atención, persuadir o modificar algún comportamiento de las audiencias a las cuales van dirigidos. Al exagerar comportamientos, rasgos y situaciones, tales contenidos invisibilizan otros aspectos de la realidad. De los argumentos aportados por los participantes, se reitera la palabra "libertad" y la expresión "ser libre", que probablemente no se hacen suficientemente explícitas en el imaginario de juventud que transmiten los comerciales: "En el comercial falta el resto de temas comportamentales de un joven, es decir, esta es solamente una etapa de la vida, que nos están vendiendo, porque un joven también lee, un joven también está en un prospecto (...)".

Las anteriores palabras muestran que la idea de joven es insuficiente desde la perspectiva de la publicidad y que esta mantiene invisibles ciertos rasgos que los participantes sí identificaron. En este orden de ideas, los imaginarios de juventud construidos por los participantes contrastan con los relatos publicitarios presentados y se muestran mucho más complejos, menos lineales; los jóvenes pueden ser libres y alocados, pero también pueden ser serios, o taciturnos, o poco audaces

Los participantes señalaron que, dadas las condiciones del mensaje y la intencionalidad de los comerciales, muchos de ellos generalizan las características del joven, excluyendo cualidades o particularidades que estos puedan tener. Por ejemplo, algunos participantes afirmaron que no todos los jóvenes tienen el comportamiento "torpe" y "tosco" del personaje de los comerciales de Open English y que no todos los periodistas novatos son tan ingenuos como el corresponsal Ricardo Jorge, personaje de las campañas de Davivienda.

Algunas frases de los participantes que apoyan esta idea son: "Yo siento que igual el comercial está bien, pero no muestra lo que es un joven como tal"; "no se puede definir la totalidad de un joven por el contexto en el que fue encajado. No se puede decir que el joven va a poder seguir pensando de la misma manera (...)". 


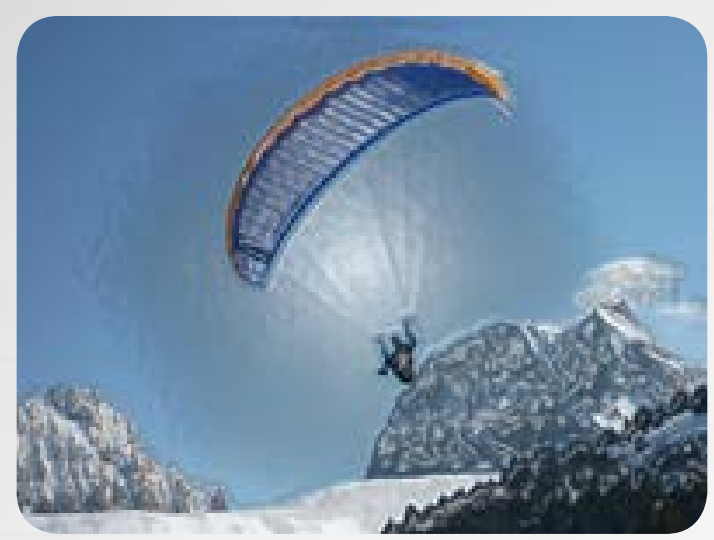

Esta última afirmación permite evidenciar una mirada menos homogénea y más situada con respecto a la juventud; es decir, la noción de joven, como la de cualquier ser humano, tiene que ver con el contexto y con la subjetividad: muchas personas en la situación que presenta el comercial, se comportarían de esa forma y podrian entonces adquirir características tradicionalmente consideradas como juveniles, pero algunos actuarían de maneras desconcertantes y no esperadas. Quizás la publicidad misma intenta eso: transpolar valores juveniles hacia otro sector de la sociedad no joven, lo cual coincide con el ideal de juvenilización de la sociedad que corre por cuenta de algunos autores.

\begin{abstract}
"La publicidad representa los valores y normas de una cultura (Goffman, 1978 citado por Mastin, Coe, Hamilton \& Tarr, 2008) y puede estar relacionada con la construcción de identidad y la definición de estilos de vida (Royo-Vela, Miquel \& Caplliure, 2002; Sandoval, 2006; Tajfel, 1978 citado por Scandroglio et al., 2008). Además, participa en la conformación y consolidación de estereotipos de género que pueden limitar el accionar de hombres y mujeres a ciertos escenarios (Yoder, Christopher \& Holmes, 2008) que no siempre reflejan los cambios sociales (Belch \& Belch, 2001; García \& Martínez, 2009), donde por ejemplo la mujer ocupa posiciones de liderazgo y alta competencia y los hombres son sociables y cálidos, ejerciendo además roles familiares" (Velandia-Morales \& Rincón, 2014, p. 519).
\end{abstract}

\subsection{Adultocentrismo}

Algunas intervenciones de los participantes identificaron ese imaginario de la relación distante entre jóvenes y adultos, entre padres e hijos, como "cliché" o lugar común: "También veo ese cliché de siempre, esa relación entre padre e hijo, que es tan indiferente, esa relación como tan lejana: no se pasa al compartir, a ser realmente amigos".

Los participantes no creen que ese imaginario tradicional adultocentrista de la juventud como etapa con características que contrastan con la adultez, esté respondiendo a una realidad, sino a una simplificación (implícita a la noción de cliché) que no contempla la posibilidad de que padres e hijos puedan compartir como "pares", es decir, como interlocutores que se validan mutuamente. Este señalamiento de los participantes se muestra, no obstante, también como un requerimiento afectivo de amistad y de diálogo.

Además, con las expresiones "cliché" y "el joven y el papá", se está aludiendo también al desconocimiento de las condiciones socio históricas de las potenciales relaciones actuales ente la juventud y la adultez. Los pares casi polares joven/padre, joven/familia, joven-objeto de educación y corrección/educadorescorrectores, son nociones inscritas en el estudio del desarrollo humano propio de campos como la psicología, que obedecen a fines industriales en el adiestramiento y economización de las fuerzas productivas.

Cuando los participantes de los grupos focales hablan de "relación lejana", se refieren no solo al vínculo históricamente situado con la autoridad, que enmarca a la juventud como etapa en la que son imprecindibles la protección y cuidado, por tratarse de un período en el que aún el desarrollo pleno no se ha alcanzado; sino también a un reclamo de fondo: ¿por qué tendría que ser lejano el vínculo entre padres e hijos?; ¿es que acaso la protección y la guía no pueden venir de la mano de un reconocimiento de los jóvenes como sujetos tan válidos como los adultos?

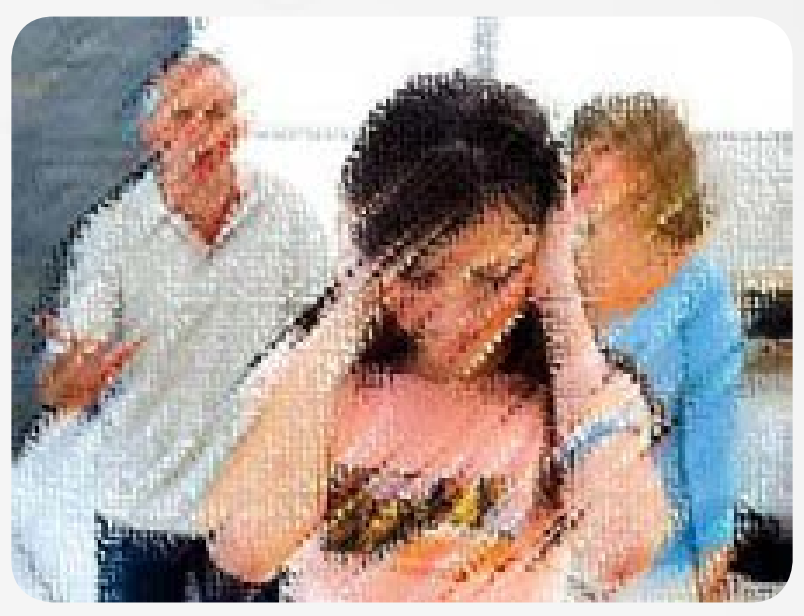

Estos señalamientos hechos por los participantes controvierten los imaginarios sociales instituidos de juventud implícitos en la teoría de tintes evolucionistas de Stanley Hall (1904), según los cuales las personas que integran esta categoría entran en una fase caracterizada por el salvajismo, tal como el período prehistórico se caracteriza por la incivilidad. "La estructura genética de la personalidad lleva incorporada la historia del género humano: cada organismo individual, en el curso de su desarrollo, reproduce las etapas que se dieron a lo largo de la evolución de la especie, desde el salvajismo a la civilización". (González y Feixa, 2013). No es de extrañar que a partir de este enfoque la adolescencia requiera de la intervención de los adultos, sobre todo a partir del sistema educativo.

Los participantes indagados parecen poner en tela de juicio tal noción del joven como "salvaje" y poco comprometido, que solo persigue la diversión. Por ejemplo, uno de ellos hace el siguienta aserto: "solo están mostrando que el joven, es el que se divierte, escucha música, sale feliz por aquí, por allá, pero entonces qué pasa con ese que se alegra leyendo un libro, o saliendo a un barrio y viendo gente, entonces es como que todos los jóvenes somos iguales. Pero entonces qué pasa con estos seres que son diferentes y que se divierten de una manera distinta".

Estas palabras exigen el reconocimiento de los jóvenes como sujetos válidos, capaces de diferenciarse y escapar a las características de los imaginarios juveniles tradicionales: la rebeldía, la alegría, la "locura"; es decir, capaces de establecer negociaciones con el Otro (representado por los padres, la institución familiar o la cultura) desde una postura flexible, que no necesariamente tenga que responder a los caracteres de salvajismo, primitivismo o amenaza. 


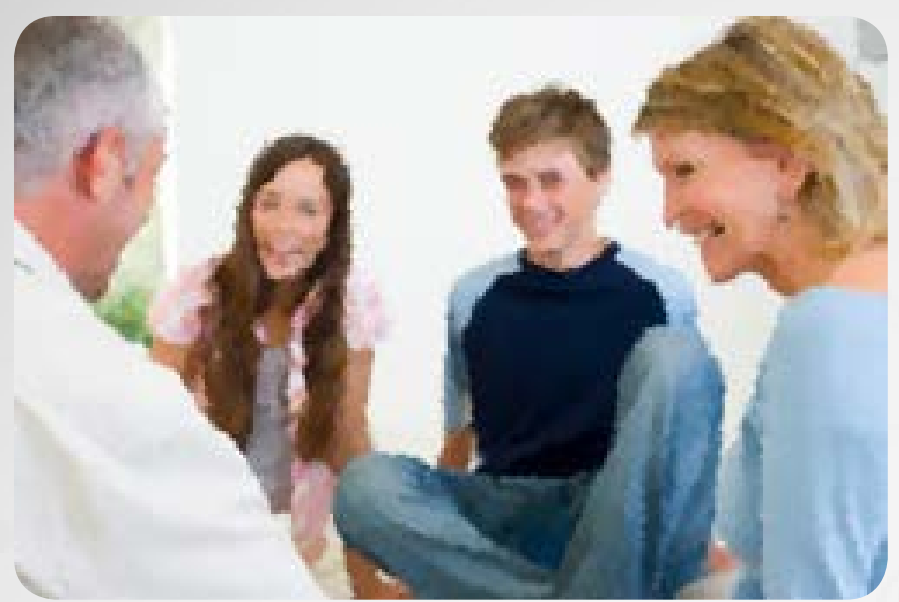

Los imaginarios propuestos por los relatos publicitarios contemporáneos son más ambiguos, pues presentan a un joven que se rebela de distinta forma, de una manera menos explícita, pero que sin embargo sigue entrando en choque con el universo de los adultos.

Los jóvenes se enfrentan con la complejidad del imaginario propuesto por el relato publicitario (el del joven en su habitación que baila solo y se detiene ante la mirada algo laxa del padre, quien se muestra confundido y pretende no haber visto nada) y responden con construcciones también complejas, cambiantes, que hacen que hablar de ello sea difícil y los enunciados se tornen confusos: están tratando de referirse a la experiencia misma de la juventud en estos tiempos, a las relaciones intergeneracionales, al cambio en los roles familiares, al padre puesto en entredicho como figura de autoridad, entre otros asuntos.

Con respecto a este último punto, el de la autoridad, los participantes en los grupos focales se refirieron a veces, como ocurrió en el análisis de otras categorías, en términos de una necesidad de guía, de ley, de límites, de garantía. Nada mejor que la figura del padre, tan en crisis en estos días, para volcar en ella tal reclamo: "yo si soy muy familiar, esa interacción entre el papá y el hijo, que el papá vea al hijo como es el hijo, y no como se comporta el hijo en la sala. Estoy casi segura de que si muestran al chico digamos en otra parte de la casa en este caso, no va a actuar de la misma manera que en su cuarto, es su espacio, su mundo digámoslo así (...) hubiera sido ideal que mostraran más ese respeto que se debe tener por la autoridad, pero ese respeto digámoslo así por las ideologías porque digamos tú tienes tu personalidad y yo tengo la mía, pero igual así podemos convivir".

\section{Conclusiones}

Los aportes hechos por los participantes en la investigación muestran que los jóvenes son capaces de reconocer en el relato publicitario ciertos estereotipos, de los cuales algunos son prejuicios, es decir, estimaciones negativas acerca de las personas y comunidades que se toman por verdaderas sin un análisis argumental previo. Entre tales estereotipos y prejuicios están los del joven eternamente alegre, desenfrenado, "loco", aventurero y opuesto a la autoridad paterno-filial, los cuales fueron contrastados con otras visiones de juventud más fragmentadas y diversas, que sitúan a los jóvenes como sujetos capaces de asumir actitudes no siempre tan predecibles, de acuerdo al contexto y a las particularidades subjetivas. Este resultado ratifica uno de los imaginarios sociales analizados por Hurtado (2004).
Por otra parte, los jóvenes participantes evidenciaron que la exageración propia de los estereotipos juveniles publicitarios es necesaria para capturar la atención y lograr un efecto hilarante, cómico o sorpresivo, pero tendieron a calificar como cualidades las actitudes de los personajes presentados cuando estos se hallaban en un contexto más íntimo, familiar y cotidiano, como por ejemplo, una habitación juvenil. Cuando los personajes eran ideales y convencionalmente deseables, tendían a calificar los estereotipos ahí presentes como lejanos e inalcanzables con respecto a su cotidianidad. Tal es el caso del joven precozmente exitoso, estereotipo cuyo carácter híbrido y cambiante lo convierte en todo un imaginario que aúna características tradicionales de la juventud y de la adultez y que por eso adquiere rasgos de complejidad difícilmente ubicables en una u otra categoría.

Inevitablemente ligadas a los estereotipos propios de los imaginarios identificados y construidos por los participantes, se evidenció la invisibilización de ciertas características potenciales de la juventud. Entre estas está cierto carácter taciturno y también algunos gustos por actividades no arriesgadas, menos espectaculares y audaces. En este sentido, la expresión "ser libre", con la que los participantes se refirieron a todo ese imaginario invisibilizador de características menos atractivas para un posible consumidor, se opone a una realidad juvenil más situada subjetiva y contextualmente: literalmente, menos libre en el sentido de menos indeterminado y sujeto a la pura tendencia individual.

En relación con esta oposición a una indeterminación constitutiva a la juventud, pareciera que los participantes, al referirse a la tradicional oposición adultocentrista entre joven y adulto como cliché, es decir como lugar común en el que se obvia el posible establecimiento de relaciones de pares entre personas de distintas generaciones, estuvieran llamando a una suerte de doble reivindicación: por un lado, la del reconocimiento de sí mismos como sujetos válidos, y por el otro, a la de la orientación requerida para asumir tal estatuto de subjetividad afirmativa bajo un garante de protección. El imaginario emergente en tal llamado aúna rasgos de indefensión y suficiencia, de moratoria y madurez, y abren la puerta a la transformación de la concepciones de juventud y de adultez, para dar lugar en ellas, respectivamente, a la afirmación y al inacabamiento, y dejar de considerarlas como etapas psicobiológica con fronteras claramente delimitadas caracterizadas por la transición y la culminación del desarrollo.

¿Qué ocurre con estos nuevos imaginarios, con estas construcciones emergentes? ¿Hay un reclamo de autoridad paternalista (en el doble sentido de padre y de protección) en una sociedad en donde la figura paterna está precisamente cada vez más "desautorizada"? Estamos ante configuraciones complejas de la relación que establecen los participantes con el relato publicitario, pues pareciera que vende originalidad y emancipación, pero ellos también pugnan por retornar a ideales de familia, lazo social, protección y apoyo.

Por último, aunque pareciera que las afirmaciones de los participantes se dirigen hacia el reconocimiento de estos imaginarios de juventud que se resisten a las tendencias homogeinizantes, "estereotipantes", invisibilizadores y adultocentristas del relato publicitario tal y como es concebido por la crítica teórica propia de las sociedades posindustriales, surge aquí la duda sobre la publicidad como arma de doble filo, capaz 
de hacer lecturas cada vez más complejas de la realidad y de los consumidores para ofrecerles lo que ahora quieren ver y escuchar: que son únicos, que no pueden ser encasillados en categorías rígidas, que tienen estilos de vida sumamente diversos y, sobre todo, que lo que buscan no puede ser suplido por el mercado. ¿Se convertirá esta presumible "diversidad" en un paradójico criterio homogenizador?

\section{Bibliografia}

Bourdieu, P. (1990). Espacio social y génesis de las clases . México: Grijalbo.

Campos, R. (2010). Juventude e visualidade no mundo contemporâneo. Uma reflexão em torno da imagem nas culturas juvenis. Sociologia, Problemas e Práticas(63), 113137.

Cepeda Sánchez, H. (2014). El eslabón perdido de la juventud colombiana. Rock, cultura y política en los años setenta. Memoria y Sociedad, 12(25), 95-106.

Colón, Eliseo (2001). Publicidad y Hegemonia. Matrices discursivas. Ed. Norma.

Duarte Q., C. (2012). Sociedades adultocéntricas: sobre sus orígenes y reproducción. Última década, 20 (36), 99-125.

Feixa, Carles. (2006). Generación XX. Teorías sobre la juventud en la era contemporánea. Revista Latinoamericana de Ciencias Sociales, Niñez y Juventud , 4(2), 21-45.

García, D., Montenegro, M., Astaíza, F., \& Martín, C. (2012). El Campo Publicitario Colombiano: Entre los imaginarios y las condiciones objetivas. Revista Nómadas(36), 254-265.

González, Y. y Feixa, C. (2013). La construcción historica de la juventud en América Latina. Bohemios, rockanroleros y revolucionarios. Santiago de Chile: Cuarto Propio.

Hall, S. G. (1904). Adolescence: Its Psychology and its relations to Psysiology, Sociology, Sex, Crime, Religion and Education. New York: Appleton Century Crofts.

Hurtado, R. (2004). Reflexiones sobre la Teoría de Imaginarios. Revista de Epistemología de las Ciencias Sociales, Cinta moebio(21), 169174.

Martínez P., Jorge E. \& Barragan G., Diego F. (2008). Juventud y multitud:

Aproximaciones para abordar los movimientos juveniles. Tabula Rasa, (9), 353-370.

Velandia-Morales, Andrea, \& Rincón, Juan Carlos. (2014). Estereotipos y roles de género utilizados en la publicidad transmitida a través de la televisión. Universitas

Psychologica, 13(2), 517-527.
Colombia: apuntes para una comprensión del relato publicitario de la modernidad. Signo y Pensamiento, (49), 160-169.

Villadiego Prins, Mirla. (2013). Narrativas del juego de la publicidad televisiva. Elementos

para una comprensión en perspectiva lúdica. Signo y Pensamiento, 32(62), 130-148.

Notas

[1] https://www.youtube.com/watch?v=ZvYITtjJmJE [2] https://www.youtube.com/watch?v=eszruKyA5tc [3] https://www.youtube.com/watch?v=8y2q4_gh7Cl [4] https://www.youtube.com/watch?v=0gPisG0f09c

Para citar este artículo:

Palacios, Ch. Janneth (2017). Jóvenes \&

Publicidad. Estereotipos, prejuicios,

invisibilización y adultocentrismo. Revista

Luciérnaga / Comunicación, Año 9, N17.

Facultad de Comunicación Audiovisual - Politécnico

Colombiano Jaime Isaza Cadavid- PCJIC \& Facultad

de Ciencias de la Comunicación - Universidad

Autónoma de San Luis Potosí- UASLP. México. Págs. 1-11.

DOI. 10.33571/revistaluciernaga.v9n17a2 orcid.org/0000-0001-5504-4455

OJS. http://revistas.elpoli.edu.co/index.php/luc/issue/ archive

Link. http://www.politecnicojic.edu.co/index.php/ revista-luciernaga 